\title{
In vitro reduction of manganese dioxide by a ferrireductase system from the white-rot fungus Phanerochaete sordida YK-624
}

\begin{abstract}
Reduction of manganese dioxide is demonstrated for an in vitro ferrireductase system that includes NADPHdependent ferrireductase and the iron-binding compound (IBC) isolated from the white-rot fungus Phanerochaete sordida YK-624. The Fe(II)-IBC complex was more effective in reducing manganese dioxide to $\mathrm{Mn}(\mathrm{II})$ than were complexes of $\mathrm{Fe}(\mathrm{II})$ and organic acids of low molecular weight such as nitrilotriacetate, although IBC also reduced manganese dioxide to $\mathrm{Mn}$ (II) in the absence of $\mathrm{Fe}(\mathrm{II})$. The generated $\mathrm{Fe}$ (III)-IBC complex was a better substrate for NADPH-dependent ferrireductase than were other ferric chelates, suggesting that the $\mathrm{Fe}(\mathrm{III})-\mathrm{IBC}$ complex is reduced to an $\mathrm{Fe}$ (II) complex by NADPH-dependent ferrireductase. Moreover, production of the Fe(III)-IBC complex by the reduction of manganese dioxide in a reaction system containing $\mathrm{Fe}(\mathrm{II})$ and IBC was observed to be coupled to reduction of the Fe(III)-IBC complex by NADPH-dependent ferrireductase. These results indicate that the ferrireductase system of $P$. sordida YK-624 plays an important role in the reduction of manganese dioxide, which is necessary for the production and function of manganese peroxidase.
\end{abstract}

Key words Phanerochaete sordida YK-624 - NADPHdependent ferrireductase $\cdot$ Iron-binding compound $\cdot$ Manganese dioxide $\cdot$ In vitro reduction

\section{Introduction}

Several species of white-rot fungi have been studied intensively in recent years because of their ability to degrade and remove lignin from wood. In response to environmental concerns and increasingly stringent emissions standards, the

H. Hirai $(\bowtie) \cdot T$. Itoh $\cdot$ T. Nishida

Faculty of Agriculture, Shizuoka University, Shizuoka 422-8529,

Japan

Tel. +81-54-238-4853; Fax +81-54-238-4852

e-mail: afhhirai@agr.shizuoka.ac.jp pulp and paper industry has been looking for ways to decrease the levels of chlorinated lignin residues in its effluents through production process changes and improved treatment technologies. The white-rot fungi Phanerochaete chrysosporium, ${ }^{1,2}$ Trametes versicolor, ${ }^{3,4} P$. sordida YK$624,{ }^{5,6}$ and IZU-154 ${ }^{7,8}$ have the ability to bleach kraft pulp. Manganese peroxidase (MnP) is a key enzyme in the biological bleaching of kraft pulp with white-rot fungi because the MnP activity levels detected in cultures have been found to be linearly correlated with the increase in brightness of the kraft pulp treated with these fungi. ${ }^{1,5,9}$

The Mn(II) ion is necessary for the production and function of MnP from P. sordida YK-624 and other fungi. ${ }^{6} \mathrm{Un}$ bleached hardwood kraft pulp (HWKP) contains Mn at a concentration of about $50 \mathrm{mg} / \mathrm{kg}$ pulp. ${ }^{6,9}$ That $P$. sordida YK-624 uses manganese from HWKP in its biological bleaching is evident from the observation that this fungus can produce MnP and brighten HWKP in cultures containing only HWKP and water. ${ }^{5,6}$ Treatment with MnP alone does not increase the brightness of HWKP without the addition of $\mathrm{MnSO}_{4}{ }^{10}$ but if oxalate is added as a manganese dioxide-reducing agent, $\mathrm{MnP}$ can brighten HWKP in vitro without exogenous $\mathrm{MnSO}_{4}{ }^{11}$ These results suggest that the manganese in HWKP occurs predominantly in the Mn(IV) oxidation state in the form of compounds such as manganese dioxide and that little $\mathrm{Mn}(\mathrm{II})$ is present. As part of the process of biological bleaching, $P$. sordida YK-624 apparently reduces manganese dioxide in HWKP to $\mathrm{Mn}(\mathrm{II})$. Electron spin resonance analysis of HWKP biobleaching with P. sordida YK-624 has confirmed that manganese dioxide $[\mathrm{Mn}(\mathrm{IV})]$ in kraft pulp is reduced to $\mathrm{Mn}(\mathrm{II}) .^{12,13}$ The reduction of manganese triggers $P$. sordida YK-624 to produce MnP, which then bleaches the kraft pulp. ${ }^{12}$

Washed mycelia of $P$. sordida YK-624 in liquid culture have been observed to reduce manganese dioxide, ${ }^{13,14}$ a process demonstrated to be dependent on $\mathrm{Fe}(\mathrm{II})$, a metal chelator, and NAD $(\mathrm{P}) \mathrm{H}$. Moreover, cell-free extracts of $P$. sordida YK-624 have been demonstrated to catalyze the reduction of ferric chelate to ferrous chelate in the presence of NAD $(\mathrm{P}) \mathrm{H} \cdot{ }^{13}$ It is likely, therefore, that ferrous chelate reduces manganese dioxide and that the ferric chelate pro- 
duced is reduced, in turn, by an intracellular $\mathrm{NAD}(\mathrm{P}) \mathrm{H}-$ dependent reductase to regenerate the ferrous chelate. ${ }^{13,14}$ An intracellular NADPH-dependent ferrireductase (molecular weight $35 \mathrm{kDa}$; $\mathrm{pI} 5.1$ ) has been purified from $P$. sordida YK-624. ${ }^{13,15}$ It is necessary for the reduction of $\mathrm{Fe}$ (III)-nitrilotriacetate (NTA) complex by the ferrireductase to add 1,10-phenanthroline (PHT) as an effective ferrous chelator to the reaction mixture. ${ }^{15}$ This result suggests that the Fe(III)-NTA complex is not a good substrate for the ferrireductase, and that PHT may play an important role in the release of $\mathrm{Fe}(\mathrm{II})$ from the ferrireductase. In short, it is probable that $P$. sordida $\mathrm{YK}-624$ produces IBC as iron chelator and that $\mathrm{Fe}(\mathrm{III})-\mathrm{IBC}$ is directly reduced by the ferrireductase. More recently, we have isolated IBC from a culture of $P$. sordida YK-624. ${ }^{16}$ IBC is probably involved in the reduction of manganese dioxide by combination with $\mathrm{Fe}(\mathrm{II})$, in the transport of iron into cells, and in the reduction of $\mathrm{Fe}$ (III) by the ferrireductase as chelator.

Here we describe the in vitro reduction of manganese dioxide by a ferrireductase system that includes NADPHdependent ferrireductase, an IBC, $\mathrm{Fe}(\mathrm{II})$, and NADPH. Particularly, we examined whether Fe(II)-IBC complex is a good electron donor for the reduction of manganese dioxide, and whether $\mathrm{Fe}(\mathrm{III})-\mathrm{IBC}$ complex is a good substrate for the ferrireductase.

\section{Materials and methods}

\section{Microorganism}

Fungus strain $P$. sordida YK-624 (ATCC 90872) was used in this study. The strain was maintained on potato dextrose agar (PDA; Difco) slants at $4^{\circ} \mathrm{C}$.

Production and purification of NADPH-dependent ferrireductase

The activity of NADPH-dependent ferrireductase was determined as described previously. ${ }^{15}$ PDA plates $(9 \mathrm{~cm}$ diameter) were inoculated with the strain and incubated for 3 days at $30^{\circ} \mathrm{C}$. Four disks punched from the growing edge of the mycelium on a PDA plate were added to a petri dish $(9 \mathrm{~cm}$ diameter) containing $20 \mathrm{ml}$ of a liquid medium and statically incubated at $30^{\circ} \mathrm{C}$ for 7 days. The liquid medium contained $1 \%$ glucose, $12 \mathrm{mM}$ ammonium tartrate, $20 \mathrm{mM}$ sodium acetate, $1 \%$ Tween $80,2 \mathrm{mM}$ vanillic acid, $14.7 \mathrm{mM}$ $\mathrm{KH}_{2} \mathrm{PO}_{4}, 2.16 \mathrm{mM}$ NTA, $2.80 \mathrm{mM} \mathrm{MgSO}, 1.72 \mathrm{mM} \mathrm{MnSO}_{4}$, $6.33 \mathrm{mM} \mathrm{NaCl}, 0.24 \mathrm{mM} \mathrm{CoSO}_{4}, 1.14 \mathrm{mM} \mathrm{CaCl}_{2}, 0.24 \mathrm{mM}$ $\mathrm{ZnSO}_{4}, 14.8 \mu \mathrm{M} \quad \mathrm{CuSO}_{4}, 14.3 \mu \mathrm{M} \quad \mathrm{AlK}\left(\mathrm{SO}_{4}\right)_{2}, 60.7 \mu \mathrm{M}$ $\mathrm{H}_{3} \mathrm{BO}_{3}, 17.8 \mu \mathrm{M} \mathrm{Na}_{2} \mathrm{MoO}_{4}$, and $3 \mu \mathrm{M}$ thiamine- $\mathrm{HCl}$, adjusted to $\mathrm{pH}$ 4.5. Fifty petri dishes were used.

Enzyme extraction was carried out as reported previously. ${ }^{15}$ The extract was fractionated by sequential additions of solid ammonium sulfate. Proteins exhibiting ferrireductase activity precipitated at 30\%-65\% ammonium sulfate saturation and were redissolved in $20 \mathrm{mM}$ sodium phosphate $(\mathrm{pH} 7.0)$. A column $(1.6 \times 10 \mathrm{~cm})$ of HiPrep 16/10 Butyl FF (Pharmacia Biotech, Upsala, Sweden) was equilibrated with $20 \mathrm{mM}$ sodium phosphate $(\mathrm{pH}$ 7.0) containing $1 \mathrm{M}$ ammonium sulfate. The protein was applied in the equilibration column, and the column was washed with $100 \mathrm{ml}$ equilibration buffer. The protein was then eluted with a linear gradient of decreasing ammonium sulfate concentration $(1 \mathrm{M}$ to $0 \mathrm{M}$; total volume $120 \mathrm{ml})$. The fractions containing NADPH-dependent ferrireductase activity were pooled and concentrated by ultrafiltration (10 kDa cutoff).

The active fraction from the HiPrep 16/10 Butyl FF column was applied to a column $(2.0 \times 50 \mathrm{~cm})$ of HiLoad $16 / 60$ Superdex $75 \mathrm{pg}$ (Pharmacia Biotech) equilibrated at a flow rate of $0.5 \mathrm{ml} / \mathrm{min}$ with $20 \mathrm{mM}$ sodium phosphate $(\mathrm{pH} 7.0)$ containing $0.1 \mathrm{M}$ ammonium sulfate. Active fractions from the Superdex $75 \mathrm{pg}$ column were desalted by passage through a PD-10 (Pharmacia Biotech) column equilibrated with $10 \mathrm{mM}$ borate buffer $(\mathrm{pH} 9.3)$ and concentrated by ultrafiltration (10 kDa cutoff). The concentrated solution was loaded onto a Mono Q HR 5/5 (Pharmacia Biotech) column equilibrated with $10 \mathrm{mM}$ borate buffer $(\mathrm{pH} 9.3)$. Unbound protein was washed off with $15 \mathrm{ml}$ of $10 \mathrm{mM}$ borate buffer ( $\mathrm{pH}$ 9.3), and the active fractions were eluted with a linear gradient of increasing ammonium sulfate concentration $(0-0.5 \mathrm{M})$ at a flow rate of $0.5 \mathrm{ml} / \mathrm{min}$. The active fractions eluted from the Mono Q column were used in the present study.

Production and purification of IBC

Iron-binding activity was confirmed by the CAS universal chemical assay. ${ }^{17}$ Four disks punched from the growing edge of the mycelium on a PDA plate were added to a petri dish $(9 \mathrm{~cm}$ diameter) containing $20 \mathrm{ml}$ of a liquid medium and statically incubated at $30^{\circ} \mathrm{C}$ for 6 days. The liquid medium contained $1 \%$ glucose, $12 \mathrm{mM}$ ammonium tartrate, $20 \mathrm{mM}$ sodium acetate, $14.7 \mathrm{mM} \mathrm{KCl}, 2 \mathrm{mM} \mathrm{MgSO}_{4}, 0.88 \mathrm{mM}$ $\mathrm{CaCl}_{2}$, and $3 \mu \mathrm{M}$ thiamine $\mathrm{HCl}$, adjusted to $\mathrm{pH}$ 4.5. Mycelial mats were separated from the cultures, and the culture fluid was filtered with a 47-mm nitrocellulose membrane filter with $0.45 \mu \mathrm{m}$ pore size (Toyo Roshi, Tokyo, Japan). The filtrate was lyophilized and dissolved in distilled water. A 2-ml aliquot of the solution was loaded onto a column of Sephadex G-25 $(1.6 \times 60 \mathrm{~cm})$ (Superfine; Pharmacia Biotech) and equilibrated with distilled water. Active fractions were used in the present study.

\section{Reduction of manganese dioxide by Fe(II)-IBC complex}

The reaction mixture $(30 \mathrm{ml})$ contained $20 \mathrm{mM}$ 2,2dimethylsuccinate $(\mathrm{pH} 4.5$ or 7.0$), 0.1 \mathrm{mM} \mathrm{FeSO}_{4}, \mathrm{IBC}$ sufficient to bind with $100 \mathrm{nmol} \mathrm{Fe}(\mathrm{III})$, and $69 \mu \mathrm{mol}$ manganese dioxide. The reaction was carried out at $30^{\circ} \mathrm{C}$ on a rotary shaker $(150 \mathrm{rpm})$ for $12 \mathrm{~h}$. The reaction mixture then was filtered with a membrane filter $(0.45 \mu \mathrm{m}$ pore size $)$, and the concentration of manganese [as soluble $\mathrm{Mn}(\mathrm{II})$ ] in the filtrate was measured by atomic absorption analysis. 
Reduction of $\mathrm{Fe}$ (III)-IBC complex by

NADPH-dependent ferrireductase

Reduction of ferric chelate by NADPH-dependent ferrireductase was determined by monitoring the oxidation of $\mathrm{NADPH}$ at $340 \mathrm{~nm}$. The reaction mixture $(1 \mathrm{ml})$ containing $20 \mathrm{mM}$ sodium phosphate ( $\mathrm{pH}$ 7.0), 0.1nkat NADPHdependent ferrireductase, $0.1 \mathrm{mM} \mathrm{FeCl}_{3}$, and IBC [sufficient to bind $3.3 \mu \mathrm{mol} \mathrm{Fe}(\mathrm{III})]$ was incubated at $30^{\circ} \mathrm{C}$. The reaction was initiated by the addition of $0.1 \mathrm{mM} \mathrm{NADPH}$. Nitrilotriacetate (NTA) $0.5 \mathrm{mM}$, citrate $2 \mathrm{mM}$, and oxalate $2 \mathrm{mM}$ were used as other ferric chelators in the present study.

In vitro reduction of manganese dioxide by ferrireductase system

Reduction of manganese dioxide by the Fe(II)-IBC complex and NADPH-dependent ferrireductase was examined as follows. In the first step, the reaction mixture $(30 \mathrm{ml})$

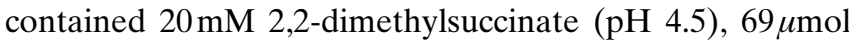
manganese dioxide, $10 \mu \mathrm{M} \mathrm{FeSO}_{4}$, and either enough IBC to bind $100 \mathrm{nmol} \mathrm{Fe}$ (III) or $12 \mu \mathrm{mol}$ NTA [which is able to bind $100 \mathrm{nmol} \mathrm{Fe}(\mathrm{III})$ in the CAS assay]. The reaction was conducted in a $100-\mathrm{ml}$ Erlenmeyer flask at $30^{\circ} \mathrm{C}$ on a rotary shaker $(150 \mathrm{rpm})$ for $6 \mathrm{~h}$. The reaction mixture was then filtered with a $0.45-\mu \mathrm{m}$ pore size membrane filter, and $100 \mu \mathrm{l}$ of the filtrate was added to the reaction mixture $(1 \mathrm{ml})$ containing $20 \mathrm{mM}$ sodium phosphate $(\mathrm{pH} 7.0)$ and $0.5 \mathrm{nkat}$ NADPH-dependent ferrireductase. The reaction was initiated by the addition of $0.1 \mu \mathrm{mol} \mathrm{NADPH}$ at $30^{\circ} \mathrm{C}$. The reduction of ferric chelates was evaluated by monitoring the oxidation of NADPH at $340 \mathrm{~nm}$.

\section{Results and discussion}

Reduction of manganese dioxide by Fe(II)-IBC

In the present study, IBC was produced in several components-omitting medium described above, different from our previous report, ${ }^{16}$ as $\mathrm{CuSO}_{4}, \mathrm{AlK}\left(\mathrm{SO}_{4}\right)_{2}, \mathrm{CoSO}_{4}, 2,2$ dimethylsuccinate, Tween $80, \mathrm{KH}_{2} \mathrm{PO}_{4}$, and NTA inhibited in the determination of iron-binding activity using the CAS universal chemical assay. The amount of IBC produced in the present medium was almost the same as that in the previous medium,${ }^{16}$ and the elution time of IBC, which was produced in the present medium, on Sephadex G-25 chromatography was the same as that in our previous medium. ${ }^{16}$ To demonstrate the extracellular reduction of manganese dioxide, the capacity of the $\mathrm{Fe}(\mathrm{II})-\mathrm{IBC}$ complex to reduce manganese dioxide to $\mathrm{Mn}$ (II) was determined. If $\mathrm{Fe}(\mathrm{II})$ reduces manganese dioxide, the reaction must obey the equation

$$
2 \mathrm{Fe}(\mathrm{II})+\mathrm{MnO}_{2}+4 \mathrm{H}^{+} \rightarrow 2 \mathrm{Fe}(\mathrm{III})+\mathrm{Mn}(\mathrm{II})+2 \mathrm{H}_{2} \mathrm{O}
$$

Therefore, the reduction of manganese dioxide to $\mathrm{Mn}(\mathrm{II})$ by $\mathrm{Fe}$ (II) depends on the $\mathrm{pH}$, and the predicted result was
Table 1. Reduction of manganese dioxide by Fe(II)-IBC complex (12h)

\begin{tabular}{lcc}
\hline Substances & \multicolumn{2}{c}{$\mathrm{Mn}(\mathrm{II})(\mu \mathrm{M})$} \\
\cline { 2 - 3 } & $\mathrm{pH} 4.5$ & $\mathrm{pH} \mathrm{7.0}$ \\
\hline $\mathrm{Fe}(\mathrm{II})+\mathrm{IBC}+\mathrm{MnO}_{2}$ & 496 & 58 \\
$\mathrm{IBC}+\mathrm{MnO}_{2}$ & 380 & 11 \\
$\mathrm{Fe}(\mathrm{II})+\mathrm{MnO}_{2}$ & 16 & 2 \\
$\mathrm{IBC}$ & 1 & 2 \\
$\mathrm{MnO}_{2}$ & 1 & 0 \\
\hline
\end{tabular}

observed (Table 1). Fe(II)-dependent generation of Mn(II) occurred more readily at $\mathrm{pH} 4.5$ than at $\mathrm{pH}$ 7.0. The Fe(II)IBC complex also reduced manganese dioxide more effectively than did $\mathrm{Fe}(\mathrm{II})$ alone (Table 1$)$. In the reaction mixture that included the Fe(II)-IBC complex (at $\mathrm{pH} 4.5$ ), $496 \mu \mathrm{M} \mathrm{Mn}(\mathrm{II})$ was detected (Table 1); however, if only $100 \mu \mathrm{M} \mathrm{Fe}(\mathrm{II})$ is present in the reaction mixture, only $50 \mu \mathrm{M}$ $\mathrm{Mn}(\mathrm{II})$ can be generated. This apparent inconsistency suggests that the IBC also functions as an electron donor for the reduction of manganese dioxide. Therefore, the possibility that IBC reduces manganese dioxide in the absence of $\mathrm{Fe}(\mathrm{II})$ was examined. As Table 1 shows, the IBC did reduce manganese dioxide to $\mathrm{Mn}(\mathrm{II})$, although the amount of $\mathrm{Mn}(\mathrm{II})$ generated by the IBC in the absence of Fe(II) was lower. The IBC also reduced Fe(III) and 2-methoxy-1,4benzoquinone (data not shown). These results indicate that the IBC functions not only as a ferric chelator but also as an electron donor. Tanaka et al. ${ }^{18}$ and Goodell et al. ${ }^{19}$ have also isolated IBCs from several wood-rot fungi, and these compounds were able to reduce molecular oxygen and ferric iron. Although the structure of the IBC from $P$. sordida YK- $624^{16}$ has not yet been identified, it is thought to reduce $\mathrm{Fe}(\mathrm{III})$ and benzoquinones by a mechanism similar to that for those compounds from other wood-rot fungi. ${ }^{18,19}$

Reduction of $\mathrm{Fe}(\mathrm{III})-\mathrm{IBC}$ complex by

NADPH-dependent ferrireductase

In our previous report ${ }^{15} \mathrm{NADPH}-\mathrm{dependent} \mathrm{ferrireductase}$ hardly reduced Fe(III)-NTA complex without PHT. In short, NTA is an exogenous chelator, not an endogenous compound. More recently, endogenous IBC was isolated from $P$. sordida YK-624. ${ }^{16}$ To demonstrate that NADPHdependent ferrireductase reduces intracellular ferrous chelates, the $\mathrm{Fe}(\mathrm{III})-\mathrm{IBC}$ complex and $\mathrm{Fe}(\mathrm{III})$-organic acid complexes were compared with respect to their abilities to serve as substrates for NADPH-dependent ferrireductase. As shown in Fig. 1, the maximum rates of NADPH oxidation by NADPH-dependent ferrireductase were obtained in reaction mixtures containing the $\mathrm{Fe}(\mathrm{III})-\mathrm{IBC}$ complex. NADPH oxidation by NADPH-dependent ferrireductase hardly occurred in the presence of $\mathrm{Fe}(\mathrm{III})$-organic acid complexes such as $\mathrm{Fe}$ (III)-NTA, Fe(III)-citrate, and $\mathrm{Fe}$ (III)-oxalate. Moreover, oxidized IBC produced with 2methoxy-1,4-benzoquinone did not affect the oxidation of NADPH by NADPH-dependent ferrireductase (data not 


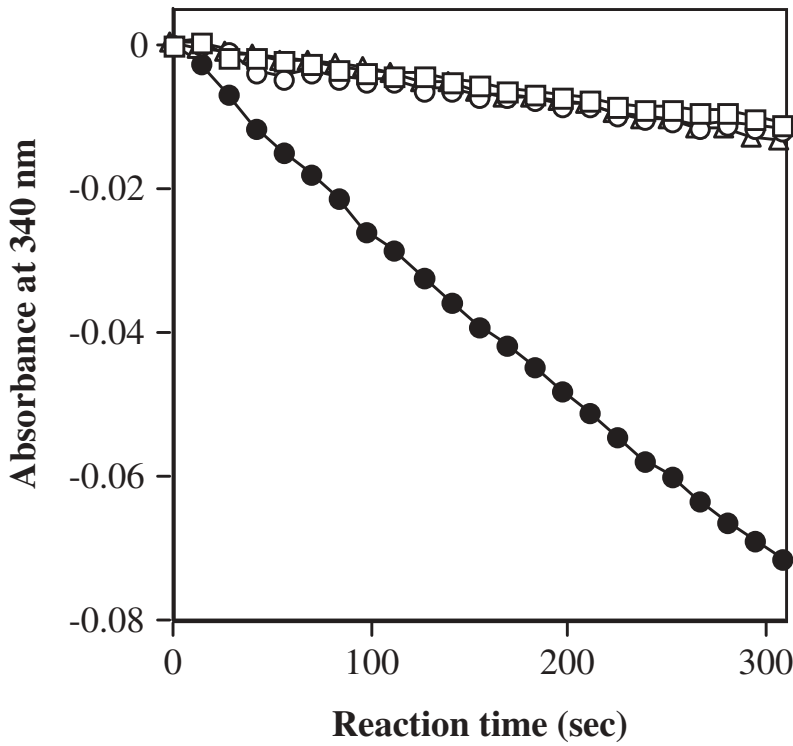

Fig. 1. Reduction of Fe(III) complexes of iron-binding compound (IBC) and organic acids by NADPH-dependent ferrireductase. These reactions were carried out at $\mathrm{pH}$ 7.0. squares, Fe(III)-NTA; open circles, Fe(III)-citrate; triangles, Fe(III)-oxalate; filled circles, Fe(III)IBC

shown). These results suggest that $\mathrm{Fe}(\mathrm{III})-\mathrm{IBC}$ complex is a good substrate for NADPH-dependent ferrireductase, and the enzyme reduces it to the $\mathrm{Fe}(\mathrm{II})-\mathrm{IBC}$ complex. On the other hand, IBC was not a substrate for NADPHdependent ferrireductase, although IBC reduced manganese dioxide to $\mathrm{Mn}(\mathrm{II})$ without $\mathrm{Fe}(\mathrm{II})$, as shown in Table 1. Therefore, Both Fe ion and IBC are necessary for the effective reduction of manganese dioxide by NADPHdependent ferrireductase.

Reduction of manganese dioxide by the ferrireductase system

We then tried to demonstrate the in vitro reduction of manganese dioxide by a two-step ferrireductase system like the one presented in Fig. 2. The first step of the experiment, the reduction of manganese dioxide by $\mathrm{Fe}(\mathrm{II})-\mathrm{IBC}$ complex, was carried out at $\mathrm{pH} 4.5$ (i.e., under extracellular conditions). In the second step, NADPH-dependent ferrireductase was used to determine if NADPH is oxidized in a reaction mixture containing $\mathrm{Fe}(\mathrm{II})-\mathrm{IBC}$ complex used in the first step of the experiment. Figure 3 demonstrates that the $\mathrm{Fe}(\mathrm{II})-\mathrm{IBC}$ complex reduced manganese dioxide to $\mathrm{Mn}(\mathrm{II})$ at a higher rate than the $\mathrm{Fe}(\mathrm{II})-\mathrm{NTA}$ complex, suggesting that the $\mathrm{Fe}(\mathrm{II})-\mathrm{IBC}$ complex is a good electron donor for manganese dioxide compared to other ferrous chelates such as the Fe(II)-NTA complex. Moreover, NADPH-dependent ferrireductase efficiently oxidized NADPH in a reaction mixture containing manganese dioxide, $\mathrm{Fe}(\mathrm{II})$, and IBC used in the first step of the experiment (Fig. 4). In contrast, the reaction mixture containing NTA instead of IBC had little effect on NADPH oxidation

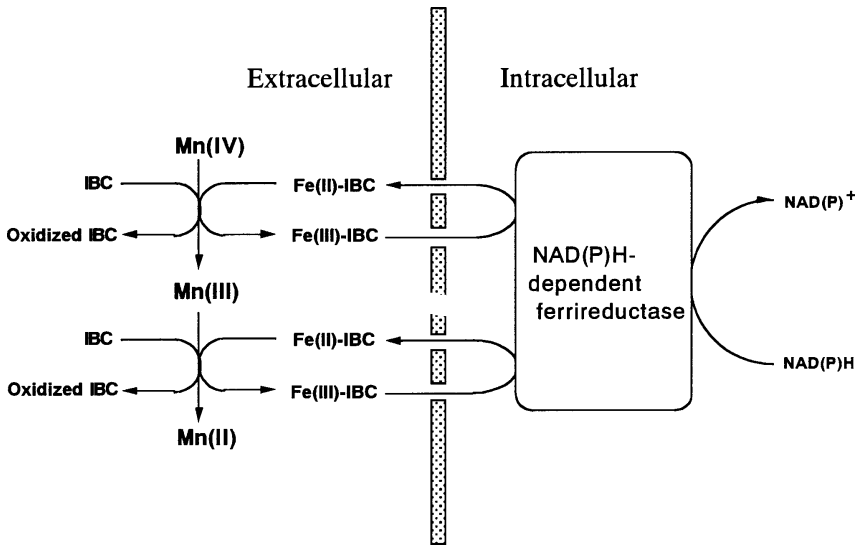

Fig. 2. Proposed mechanism of manganese dioxide reduction by the ferrireductase system of $P$. sordida YK-624

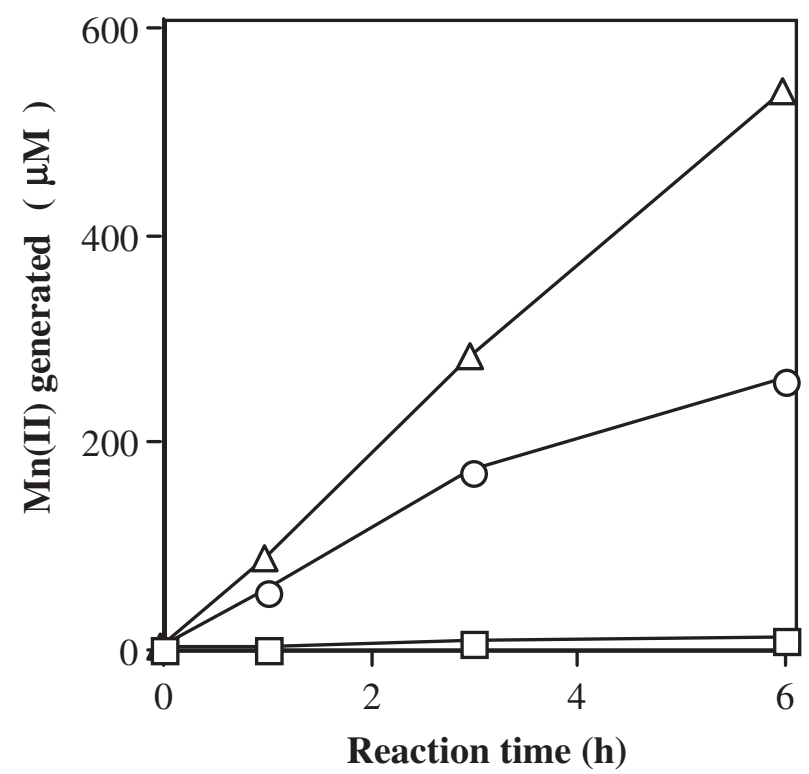

Fig. 3. Reduction of manganese dioxide by $\mathrm{Fe}(\mathrm{II})-\mathrm{IBC}$ complex. Squares, Fe(II); circles, Fe(II)-NTA; triangles, Fe(II)-IBC

by NADPH-dependent ferrireductase (Fig. 4). These results suggest that the $\mathrm{Fe}(\mathrm{II})-\mathrm{IBC}$ complex is a good electron donor for manganese dioxide and that the $\mathrm{Fe}(\mathrm{III})-$ IBC complex is a substrate for NADPH-dependent ferrireductase.

\section{Conclusions}

Several findings of the present study demonstrated in vitro reduction of manganese dioxide by a ferrireductase system that includes NADPH-dependent ferrireductase and the IBC from P. sordida YK-624. First, the Fe(II)-IBC complex was a good electron donor for reduction of manganese dioxide, although IBC also reduced manganese dioxide to 


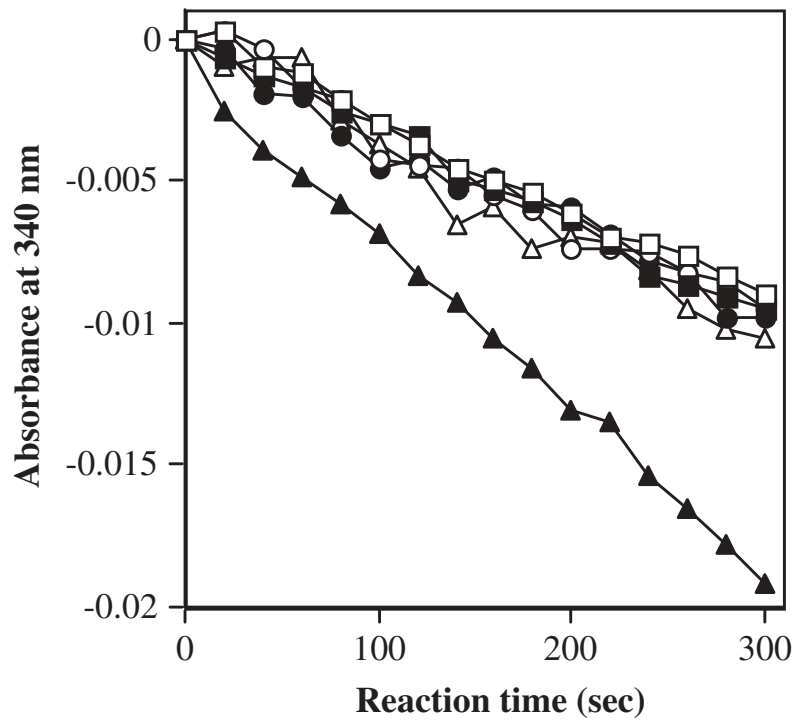

Fig. 4. Effect of the reaction mixture composition of the first step of the experiment on the oxidation of NADPH by NADPH-dependent ferrireductase. Open squares, with $\mathrm{Fe}(\mathrm{II})$ at $0 \mathrm{~h}$ incubation; filled squares, $\mathrm{Fe}(\mathrm{II})$ after $6 \mathrm{~h}$ of incubation; open circles, with $\mathrm{Fe}(\mathrm{II})-\mathrm{NTA}$ at $0 \mathrm{~h}$; filled circles, with $\mathrm{Fe}(\mathrm{II})-\mathrm{NTA}$ after $6 \mathrm{~h}$; open triangles, with $\mathrm{Fe}(\mathrm{II})$ IBC at $0 \mathrm{~h}$; filled triangles, $\mathrm{Fe}(\mathrm{II})-\mathrm{IBC}$ after $6 \mathrm{~h}$

$\mathrm{Mn}(\mathrm{II})$. Second, the Fe(III)-IBC complex was a ferric substrate of NADPH-dependent ferrireductase, but IBC was not. Finally, production of the Fe(III)-IBC complex by the reduction of manganese dioxide in a reaction system containing $\mathrm{Fe}(\mathrm{II})$ and IBC was coupled to the reduction of the Fe(III)-IBC complex by NADPH-dependent ferrireductase. These results strongly support the hypothesis that the reduction of manganese dioxide by $P$. sordida $\mathrm{YK}-624$ is caused by the mechanism presented in Fig. 2, and that the ferrireductase system including IBC as both electron donor and iron chelator is necessary for the production and function of manganese peroxidase. The reducing mechanism of oxidized IBC by $P$. sordida YK-624 is being examined in detail and will be reported in a forthcoming paper.

\section{References}

1. Katagiri N, Tsutsumi Y, Nishida T (1995) Correlation of brightening with cumulative enzyme activity related to lignin biodegradation during biobleaching of kraft pulp by white rot fungi in the solid-state fermentation system. Appl Environ Microbiol 61:617622
2. Katagiri N, Tsutsumi Y, Nishida T (1995) Extracellular reducing enzyme during biobleaching of hardwood kraft pulp by white-rot fungi. Mokuzai Gakkaishi 41:780-784

3. Paice MG, Jurasek L, Ho C, Bourbonnais R, Archibald F (1989) Direct biological bleaching of hardwood kraft pulp with the fungus Coriolus versicolor. TAPPI J 72:217-221

4. Reid ID, Paice MG, Ho C, Jurasek L (1990) Biological bleaching of softwood kraft pulp with the fungus Trametes versicolor. TAPPI J 73:149-153

5. Hirai H, Kondo R, Sakai K (1994) Screening of lignin-degrading fungi and their ligninolytic enzyme avtivities during biological bleaching of kraft pulp. Mokuzai Gakkaishi 40:980-986

6. Hirai H, Kondo R, Sakai K (1995) Effect of metal ions on biological bleaching of kraft pulp with Phanerochaete sordida YK-624. Mokuzai Gakkaishi 41:69-75

7. Fujita K, Kondo R, Sakai K, Kashino Y, Nishida T, Takahara Y (1991) Biobleaching of kraft pulp using white-rot fungus IZU-154. TAPPI J 74:123-127

8. Fujita K, Kondo R, Sakai K, Kashino Y, Nishida T, Takahara Y (1993) Biobleaching of softwood kraft pulp using white-rot fungus IZU-154. TAPPI J 76:81-84

9. Paice MG, Reid ID, Bourbonnais R, Archibald F, Jurasek L (1993) Manganese peroxidase, produced by Trametes versicolor during pulp bleaching, demethylates and delignifies kraft pulp. Appl Environ Microbiol 59:260-265

10. Kondo R, Harazono K, Sakai K (1994) Bleaching of hardwood kraft pulp with manganese peroxidase secreted from Phanerochaete sordida YK-624. Appl Environ Microbiol 60:4359-4363

11. Harazono K, Kondo R, Sakai K (1996) Bleaching of hardwood kraft pulp with manganese peroxidase from Phanerochaete sordida YK-624 without addition of $\mathrm{MnSO}_{4}$. Appl Environ Microbiol 62:913-917

12. Hirai H, Oniki T, Kondo R, Sakai K (2000) Change in oxidation state of manganese atoms in kraft pulp during biological bleaching with white-rot fungus Phanerochaete sordida YK-624. J Wood Sci 46:164-166

13. Hirai H, Itoh T, Kondo R, Sakai K, Nishida T (2002) Intracellular ferrireductase involved in $\mathrm{Mn}(\mathrm{IV})$-reducing enzyme system to supply $\mathrm{Mn}(\mathrm{II})$ for lignin biodegradation by white-rot fungus Phanerochaete sordida YK-624. Enzyme Microbiol Technol 30: 467-473

14. Hirai H, Kondo R, Sakai K (1997) A model system for NAD(P)Hdependent reduction of manganese dioxide mediated by ferrous chelate in white-rot fungus Phanerochaete sordida YK-624. Mokuzai Gakkaishi 43:247-253

15. Hirai H, Kondo R, Sakai K (1998) NADPH-dependent ferrireductase produced by white-rot fungus Phanerochaete sordida YK624. J Wood Sci 44:369-374

16. Hirai H, Onitsuka A, Kondo R, Sakai K, Nishida T (2001) Ironbinding compounds produced by white-rot fungus Phanerochaete sordida YK-624. J Wood Sci 47:374-377

17. Schwyn B, Neilands JB (1987) Universal chemical assay for the detection and determination of siderophores. Anal Biochem 160:46-56

18. Tanaka H, Itakura S, Enoki A (1999) Hydroxyl radical generation by an extracellular low-molecular-weight substance and phenol oxidase activity during wood degradation by the white-rot basidiomycete Trametes versicolor. J Biotechnol 75:57-70

19. Goodell B, Jellison J, Liu J, Daniel G, Paszcynski A, Fekete F, Krishnamurthy S, Jun L, Xu G (1997) Low molecular weight chelators and phenolic compounds isolated from wood decay fungi and their role in the fungal biodegradation of wood. J Biotechnol 53:133-162 